\title{
THE VALUE OF COMMUNITY ENGAGEMENT IN BOTANIC GARDENS WITH EXAMPLES FROM THE ROYAL BOTANIC GARDEN EDINBURGH
}

\author{
Jenny Foulkes ${ }^{l}$
}

\begin{abstract}
The Royal Botanic Garden Edinburgh (RBGE) has community engagement at its core. With health and environmental challenges facing society, its mission "to explore, conserve and explain the world of plants for a better future" is more important and relevant than ever. The established community engagement programme at RBGE includes the Edible Gardening Project and activities at the Botanic Cottage and these are described here. Programmes explore food-growing skills and focus on improving health and wellbeing. Significant impact has occurred at the level of the individual and community, while the wider impact on the health of society and on biodiversity while implied remains to be fully assessed.
\end{abstract}

\section{INTRODUCTION AND BACKGROUND}

The Royal Botanic Garden Edinburgh (RBGE) has had community engagement at its core from the start. When the Garden was established in 1670 by Sir Robert Sibbald and Dr Andrew Balfour they did so because of their concern for the health and wellbeing of the people of Edinburgh. They wanted to improve the education of doctors and apothecaries, so that Edinburgh's population would receive the best medical treatments of the day. Creating a physic garden of herbs with medicinal uses as an educational resource allowed them to bring the world of plants directly to their students.

RBGE still aims to provide public benefit, value and opportunities for all. In a world affected by social and environmental challenges such as an ageing population, an obesity epidemic (James et al., 2001), nature deficit disorder (Louv, 2008), biodiversity loss and the impact of climate change, botanic gardens have a significant role to play in connecting people to the natural world and addressing some of these issues. The RBGE mission, "to explore, conserve and explain the world of plants for a better future", is more important and relevant than ever.

RBGE is passionate about working with communities and reaching out to all, irrespective of age, background or ability, and it is of particular importance that we find ways of including those who face barriers to engaging with us, whether they are perceived, physical, social, financial or cultural. Over the past five years the programme has expanded, working with leaders of community groups and agencies, to facilitate access to projects and programmes that inspire and inform people who might not otherwise connect with the Garden and its work.

1. Jenny Foulkes is Community Engagement Manager at the Royal Botanic Garden Edinburgh.

Address: 20A Inverleith Row, Edinburgh EH3 5LR, UK.

Email: J.Foulkes@rbge.org.uk 


\section{THE EDIBLE GARDENING PROJECT}

The Edible Gardening Project is an established part of the RBGE community engagement programme which started in May 2011. It is funded by Players of People's Postcode Lottery. The mission of the project is to share horticultural knowledge, skills and enthusiasm for growing food with diverse communities and the vision is a world where we connect better with the plants that nourish us.

The Project has a team of around 30 volunteers who help us to look after the vegetable plots, fruit garden and a polytunnel in the Demonstration Garden area at the Edinburgh Garden. The volunteers also help out with the programme of public events and community workshops. They are crucial to the success of the Edible Gardening Project, contributing over 250 hours a month and bringing skills, energy and enthusiasm.

\section{Public events}

The public events programme consists of weekly drop-in sessions and family-focused weekend events every quarter. The weekly 'Meet the Edible Gardening Team' sessions are an opportunity for live interpretation of the fruit and vegetable growing sections, where the public can obtain vegetable gardening advice, find out about seasonal tasks and tour the area.

Our weekend events are aimed at a family audience. The flagship Harvest Festival in September each year is a vibrant and popular event that includes a community gardens' produce show, music, tasters of garden produce and importantly hands-on activities that directly engage people with plants. The aim is to influence people's values and behaviours by giving them the opportunity to interact with plants on a practical level. We hope that they will begin to feel a connection to plants and the natural world and therefore nurture a desire to grow and protect them. Blackmore et al. (2013) explain that "our experience of nature helps strengthen intrinsic values, fostering concern for others as well as the natural world".

\section{Community groups programmes}

In addition to public events there are programmes for local community groups. These groups can either take part in an ongoing programme or make a one-off visit for a workshop or tour. As our funding is unrestricted (rather than being linked to delivering specific outcomes) we are able to be flexible and better able to meet the needs of the groups that we work with.

The community vegetable plots are a popular and ongoing programme. Groups take ownership of a plot for the growing season and visit the garden for a few hours a week, working alongside our knowledgeable and experienced community gardeners. They plan, propagate, maintain, harvest, prepare and share their crops.

This programme developed as a result of involvement with the Botanic Gardens Conservation International's (BGCI) and Calouste Gulbenkian Foundation's 
'Communities in Nature' programme in 2012 (Lynch, 2015). Since then, 11 organisations have held plots at RBGE. Groups attend with their own staff and volunteers who have expertise in their area, such as youth work. The advantage of holding the activities in the botanic garden is that staff can be provided with excellent horticultural training to complement the skills that come with the group. In 2017 we are welcoming Garvald (who support adults with learning disabilities), TEENS+ (a charity for young people with complex additional support needs) (Fig. 1) and Macmillan Move More (for people affected by cancer, a programme of activity to help increase activity and fitness to aid recovery).

The Macmillan Move More group joined the programme in 2016, after a very successful growing season. One of the participants has since joined the Project's volunteer team. She says, "Being part of the Edible Gardening Project has been an amazing experience for me. It has really helped me mentally as well as physically; for the first time since my illness I've felt useful."

We are not just teaching horticultural skills, we are building our own community with the people who come and experience the space. Edible Gardening Project staff also see that participants experience physical and mental health benefits associated with spending time outside in greenspace connecting with our natural environment. Marcus $\&$ Sachs (2014) discuss a wide range of evidence and research to support the restorative benefits of spending time outside in green environments. The King's Fund Report of Gardens and Health (Buck, 2016) looks specifically at the positive health outcomes from being involved in gardening activities. Research results presented in these reviews align closely with RBGE staff's experiences in witnessing health changes in individuals who have recognised the mental, physical and social improvements in their lives while volunteering with us. The nurturing nature of gardening is well aligned to promoting wellbeing and the kind of benefits we see are in raised confidence levels, feeling a sense of purpose and having a routine, all of which are often missing after periods of poor mental health and, on occasion, loss of employment. This can lead to better appetite, not least because the volunteers grow and harvest vegetables and come together to cook and eat. These are all recognised elements of the recovery model in mental health - having a sense of purpose, a sense of hope and social connection is key for recovery. Sophia Shaw (2015a; 2015b) also describes the positive mental and physical effects of visiting and working in botanic gardens.

The increasing body of evidence has led to a growth of interest from the medical profession in the benefits of a 'green prescription'. We are particularly pleased to have had our first such referral from the NHS to the Edible Garden Project. In July 2017, we worked with the Child and Adolescent Mental Health Services (CAHMS) in Edinburgh to devise a programme for young people with poor mental health. We are now beginning the process of measuring outcomes in this area.

In addition to the plots programme a range of free workshops to local community groups are offered, either based at RBGE or delivered offsite. These cover subjects such as composting, organic pest and disease control, or simply offer a tour of the garden. 
Importantly, we are able to develop sessions based on what the community groups want and need, whereby groups can pick something we already have or ask for a tailored session.

\section{WHAT NEXT? THE BOTANIC COTTAGE}

The Botanic Cottage was formally opened in December 2015. This is a new community and education centre located on the north side of RBGE in Edinburgh (Fig. 2). This building has a fascinating story: it was built in 1765 and stood at the entrance of RBGE when the Garden was located on Leith Walk, Edinburgh. RBGE subsequently moved to a new site at Inverleith and, 250 years after it was first constructed, the cottage, still on Leith Walk, had fallen into disrepair and was due for demolition. A community campaign helped to save the building and with the support of the Heritage Lottery Foundation and other funders it was moved stone by stone a mile across the city to its current location in the Demonstration Garden at RBGE (Forsyth, 2016).

The Botanic Cottage has provided RBGE with a valuable resource. It has a dry indoor space with access to a kitchen, toilet facilities, potting shed and classrooms and all of these have enabled the expansion of the community programme.

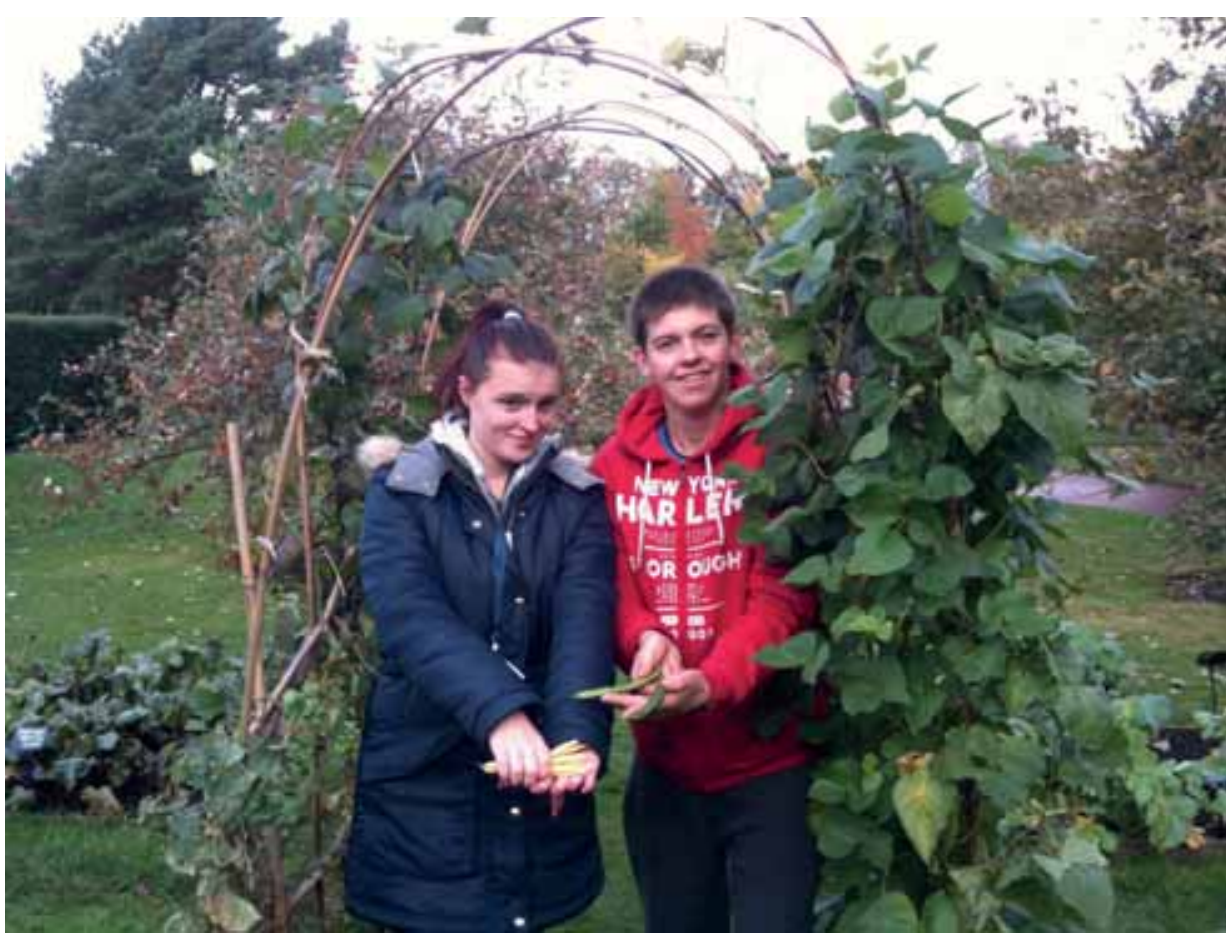

Fig. 1 TEENS+ participants in the Edible Gardening Project. Photo reprinted with permission of TEENS+. Charity number: SCO27560. 


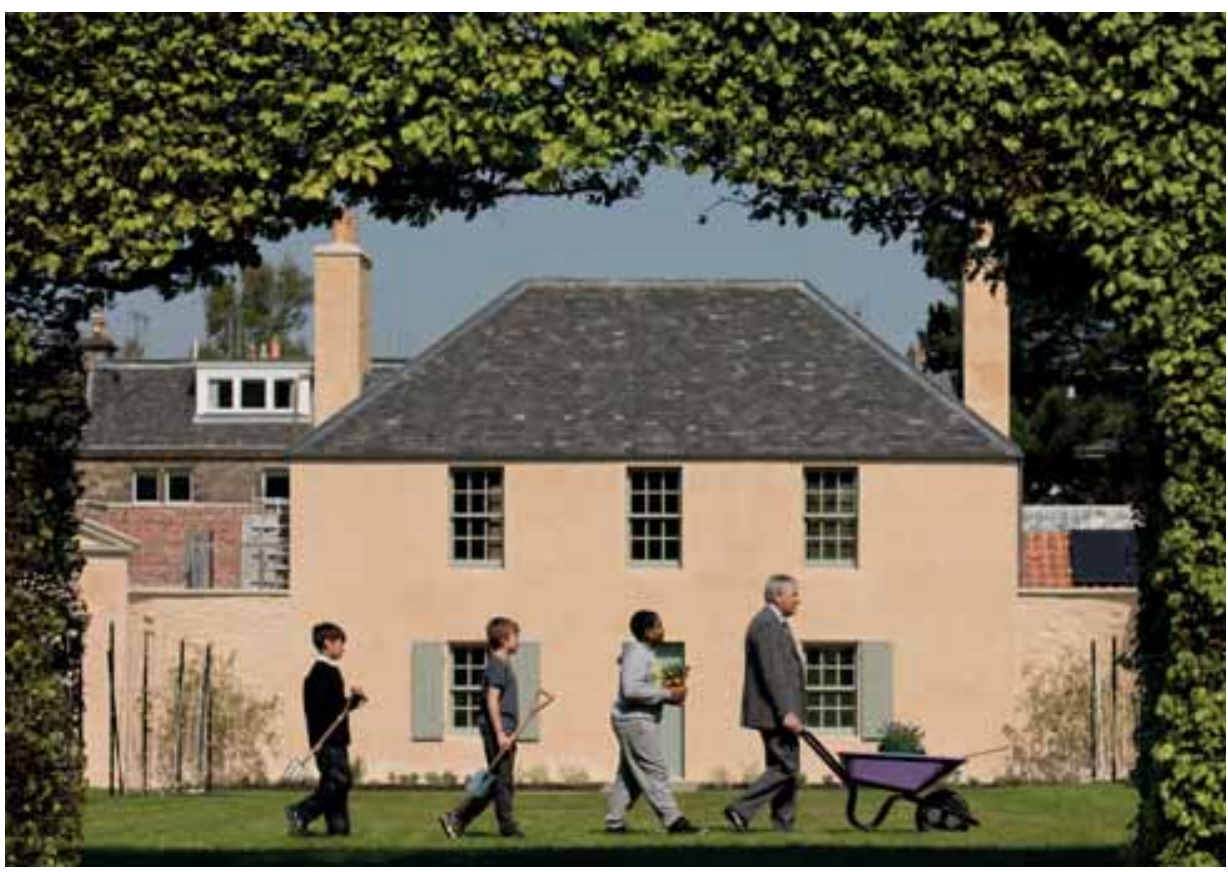

Fig. 2 The Botanic Cottage, pupils of Broughton High School and the former resident of the Cottage. Photo: Lynsey Wilson.

This flexible and responsive approach means that we can respond to the needs of our community. Local charity Nari Kallyan Shangho (NKS) offers support to South Asian women. The group was involved in our community plot programme for two years and in 2016 was looking for a new direction. NKS received funding from the Scottish Government's Climate Challenge Fund and wanted to create a new recipe book of traditional dishes using Scottish seasonal crops. The group was able to develop and try out recipes at the Botanic Cottage with participants harvesting crops directly from the Edible Garden Project and preparing and sharing the food just metres away from where it was grown (Figs $3 \& 4$ ).

As we continue to build our community at RBGE, we have found, not surprisingly, that food is a positive and effective way of bringing people together. The women from NKS delight in sharing their cooking and have provided meals for our volunteers and staff, and even made lunch for an unrelated storytelling event that was happening upstairs in the cottage, much to the delight of the visitors.

The key to the success of the Community Programme is its ability to be flexible and respond to the needs of the community. Increasingly we are asked to host programmes that are connected to health and wellbeing. The 1992 Earth Summit in Rio de Janeiro documented that human health is intrinsically linked to the environment: "the world's leaders recognised the importance of investing in improvements to people's health 


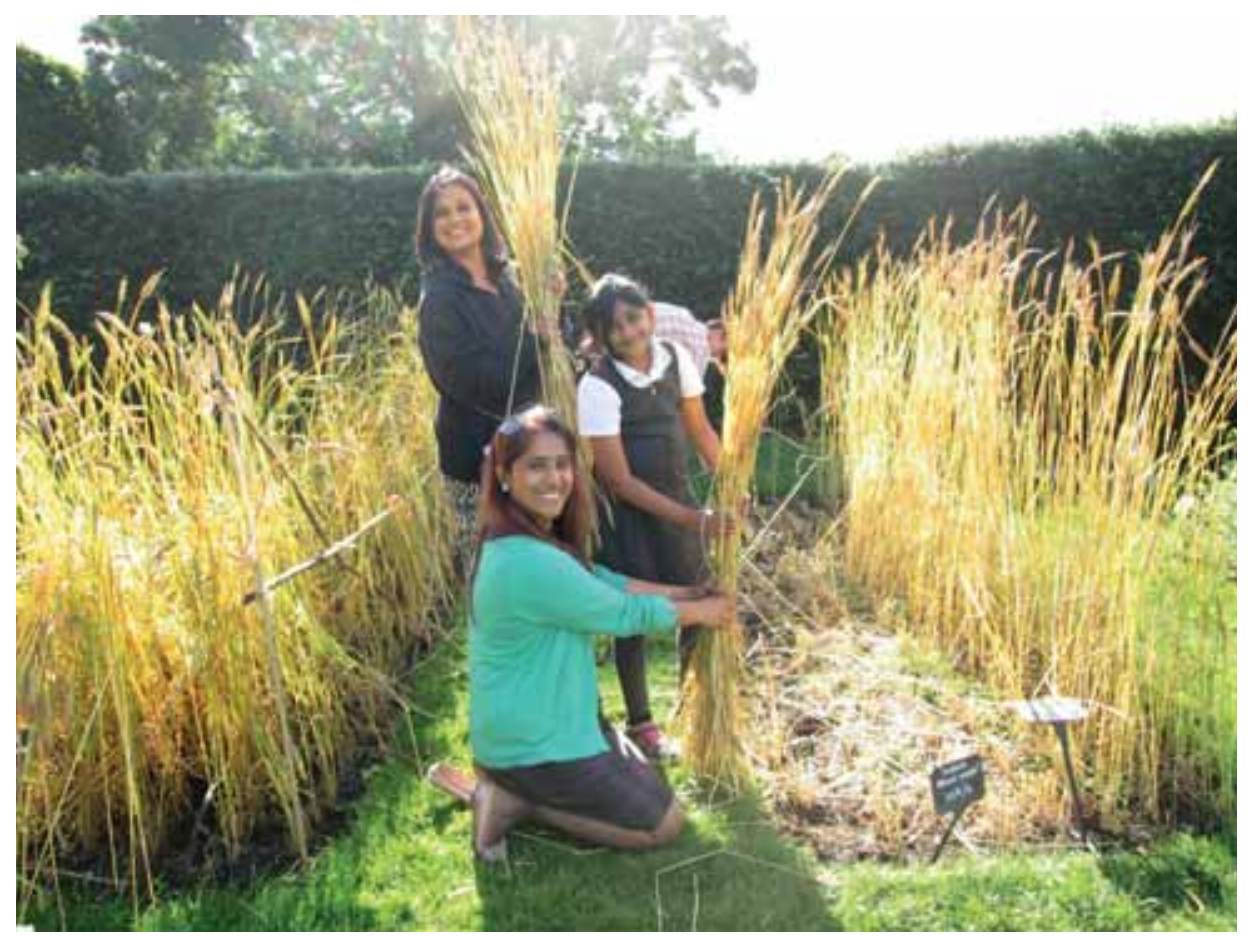

Fig. 3 Edinburgh and Lothians Regional Equality Council harvesting from their plot at RBGE. Photo: Andy Crofts.

and their environment as a prerequisite for sustainable development" (World Health Organization, 1997). The health agenda is where RBGE has its roots and as an environmental organisation we are ideally suited to responding to our community's needs. Many groups that visit the cottage have strong links to the field of health and wellbeing. We now host a monthly dementia-friendly social and a weekly art club for people with Parkinson's disease. We have worked with groups such as Kindred, a charity which supports young people with additional support needs and their families, Pilton Community Health Project and Stepping Stones, a support group for young parents.

\section{CONCLUSION AND FUTURE PLANS}

Lynch (2015) points out that "the shift is towards creating opportunities for people to do something, to work with botanic gardens - in towns, cities, countryside - and help make change happen". By giving people the opportunity for positive experiences in our environment we can then encourage them to value plants and biodiversity. Building communities, improving the health of individuals and protecting the future of plants and their habitats are seen as complementary and mutually supportive aims. By inspiring individuals and communities to feel part of our environment, rather than separate from 


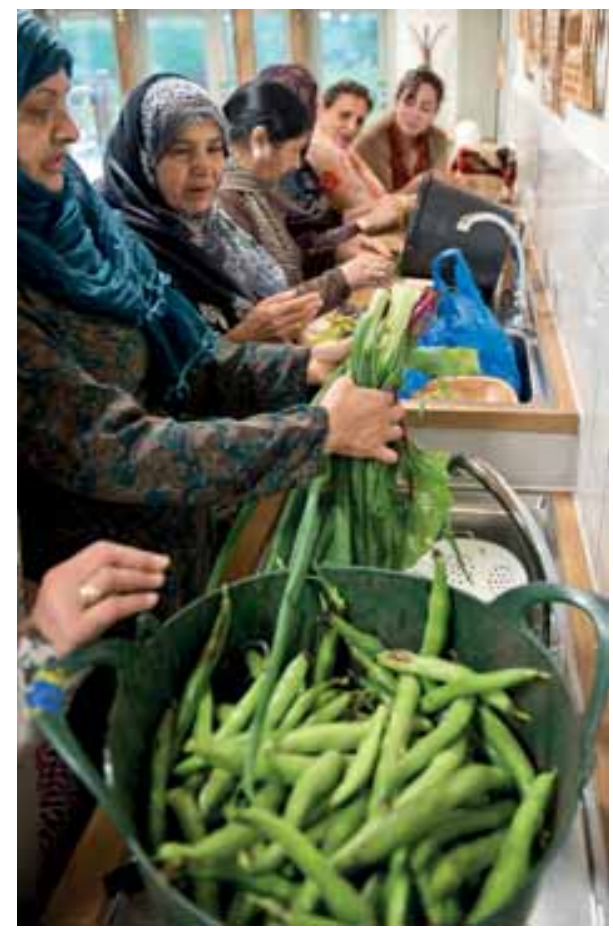

Fig. 4 Nari Kallyan Shangho preparing crops grown at RBGE. Photo: Lynsey Wilson.

it we connect them with our shared mission "to explore, conserve and explain the world of plants for a better future".

Anecdotally we know that it is not only those involved with programmes who gain health benefits from being here but also many of the regular visitors to RBGE, who say that the activities in the Edible Gardening Project and the Botanic Cottage help them with everyday stress and anxiety and can help relieve depression or aid in their recovery from trauma in their lives. We see the future of RBGE's community programme in responding to the health and wellbeing needs of the wider community and plan to research the links between both passive and active engagement with gardens and human health.

RBGE is home to a very special combination of world-class greenspace, scientific and horticultural knowledge, and passionate, accomplished people. This puts it and other botanic gardens across the world in a unique position to make a real and lasting impact on the contribution that community engagement can make to improve the health of society and the environmental sustainability of our planet.

\section{ACKNOWLEDGEMENTS}

Many thanks to Sutherland Forsyth for background information on the history of RBGE and to Dr Ian Edwards for advice and guidance. With thanks to Judy Paul for additional consultation. 


\section{REFERENCES}

BLACKMORE, E., UNDERHILL, R., MCQUILKIN, J., LEACH, R. \& HOLMES, T. (2013). Common Cause for Nature. Public Interest Research Centre, Machynlleth.

BUCK, D. (2016). Gardens and Health: Implications for Policy and Practice. Kings Fund, London.

FORSYTH, S. (2016). Discover the Botanic Cottage. RBGE, Edinburgh.

JAMES, P.T., LEACH, R., KALAMARA, E. \& SHAYEGHI, M. (2001). The Worldwide Obesity Epidemic. Obesity Research, 9, 228S-233S. doi:10.1038/oby.2001.123

LOUV, R. (2008). Last Child in the Woods. Algonquin Books, Chapel Hill, NC.

LYNCH, B. (2015). How Can Botanic Gardens Grow Their Social Role? Lessons from the Communities in Nature Programme. Calouste Gulbenkian Foundation, London.

MARCUS, C. \& SACHS, N. (2014). Therapeutic Landscapes: an evidence based approach to designing healing gardens and restorative outdoor spaces. John Wiley and Sons, Hoboken, NJ.

SHAW, S. (2015a). Guest Essay: Gardening and mental health. Sibbaldia, 13, 3-15.

SHAW, S. (2015b). The positive effects on mental health of visiting botanic gardens. Sibbaldia, $13,51-60$.

WORLD HEALTH ORGANIZATION (1997). Health and Environment in Sustainable Development: Five Years after the Earth Summit. Programmes on Health and Environment, Geneva. 